\title{
Superior Gluteal Artery
}

National Cancer Institute

\section{Source}

National Cancer Institute. Superior Gluteal Artery. NCI Thesaurus. Code C32688.

Either of two (superior or inferior) arteries branching from the internal iliac artery in the hip joint and gluteal region. 